\title{
Die Schweizerische Entwicklungszusammenarbeit : Verwirklichungen
}

La Coopération de la Suisse au développement : politique et réalisations

Jacques Forster

\section{(2) OpenEdition}

\section{Journals}

Édition électronique

URL : http://journals.openedition.org/sjep/970

DOI : $10.4000 /$ sjep. 970

ISSN : 1663-9677

Éditeur

Institut de hautes études internationales et du développement

\section{Édition imprimée}

Date de publication : 31 août 1982

Pagination : 181-206

ISSN : 1660-5926

\section{Référence électronique}

Jacques Forster, «Die Schweizerische Entwicklungszusammenarbeit : Verwirklichungen »,

Schweizerisches Jahrbuch für Entwicklungspolitik [En ligne], 2 I 1982, mis en ligne le 28 janvier 2013,

consulté le 08 septembre 2020. URL : http://journals.openedition.org/sjep/970 ; DOI : https://doi.org/ $10.4000 /$ sjep. 970

\section{Ce document a été généré automatiquement le 8 septembre 2020}

(C) The Graduate Institute 


\title{
Die Schweizerische
}

\section{Entwicklungszusammenarbeit : Verwirklichungen}

\author{
La Coopération de la Suisse au développement : politique et réalisations
}

Jacques Forster

\section{NOTE DE L'ÉDITEUR}

Zusammenfassung auf Deutsch. Volltext auf Französisch in Annuaire suisse de politique de développement: „La Coopération de la Suisse au développement : politique et réalisations ", http://aspd.revues.org/1132.

\section{RÉSUMÉS}

Dieser Bericht vermittelt einen umfassenden und doch kurzen Überblick über die schweizerische Politik der Entwicklungszusammenarbeit und deren seit ihrem, im Vergleich mit anderen Industrieländern, relativ späten Entstehen. Die der Entwicklungspolitik - der humanitäre Grundgedanke und die Vertidigung schweizerischer Interessen- und deren mitunter konfliktträchtigen Synthese zu einem Instrument der Förderung eigenständiger Entwicklung der Entwicklungsländer sind dargestellt und, besonders in ihrer Evolution der 70er Jahre, auseinandergesetzt. Der politischen Analyse sind dann die Ausführungsprinzipien, Formen, Schwergewichte, Verteilung und quantitative Evolution der tatsächlichen Entwicklungsleistungen der Schweiz gegenüber-gestellt. Die Schlussfolgerung blickt in die Zukunft: infolge ihrer Verflechtungen hat die Schweiz ein grundsätzliches und wichtiges 
Interesse an der Fortführung einer verbesserten Entwicklungshilfe und -zusammenarbeit. Die Möglichkeiten dafür bestehen heute, schon weil die Öffentlichkeit besser und umfassender über die Wichtigkeit der Nord-Süd-beziehungen informiert ist. Es bestehen heute zwar wenig Möglichkeiten für eine erhebliche Verbesserung der quantitativen Leistungen, doch besteht noch Spielraum in quantitativer Hinsicht (Ungebundenheit der Hilfe, bessere finanzielle Bedingungen, vermehrte Beteiligung an den lokalen und laufenden Kosten von Entwicklungsprojekten). Trotz des gespannten und reichlich debattierten Beziehungsfeldes der Aussenwirtschafts- und der Entwicklungspolitik kann man heute einen Ausbau wirtschaftlicher Instrumente des Entwicklungszusammenarbeit feststellen, und eine Beibehaltung des entwicklungspolitischen Gleichgewichtes der vergangenen Jahre scheint möglich zu sein. 